ESSAY

\title{
The Journal Sever and The Free Discussion Society on Harbin and Vladivostok
}

\author{
Katsumi Fujiwara \\ (Osaka University)
}

This paper introduces the Japanese periodical Sever, which is published once a year, and its publication body, The Free Discussion Society on Harbin and Vladivostok, which is now popularly called the "Sever workshop."

According to Noriko Uchiyama-Valuev," the launching process of Sever began when she entered graduate school, where she was introduced to The Free Discussion Society on Harbin and Vladivostok. This group was organized by four expatriates from Harbin. One of their members had passed away shortly afterward (around 1995), but the others, namely the late Professor Yoshikatsu Koizumi of Kansai University and the late Kango Matsuno (Russian teacher and interpreter), who were both from Harbin Academy, and the late Kimiko Sugiyama, author of the book, Harbin Story, ${ }^{* *}$ along with Uchiyama decided to publish the findings of a particular workshop. Thus, in October of 1995, the first edition of Sever was issued.

The first printing resembled a small pamphlet, and it included only four articles totaling 48 pages; it consisted of an irregular format of 32 pages of writing from left to right and 16 pages of writing from top to bottom. After this debut, they published around 60 journal pages once or twice a year. Then the late Takeshi Sakon of Osaka City University joined as a member, and, subsequently, Michiko Ikuta (Osaka University of Foreign Studies) — the current president

* Uchiyama-Valuev N. (2010), "In memory of Yoshikatsu Koizumi and Kimiko Sugiyama," Sever No.26, pp. 135-138. (In Japanese)

** Sugiyama K. (1985), Harbin story: it started from Vladivostok, Chikyukan. (In Japanese) 
of the society - was invited to the workshop by Sakon and started writing articles in issue Number 9 in 1999, continuing to the present. ${ }^{* * *}$

The purpose of releasing the journal was cited briefly on its back cover:

Long Ago, the "Northern Places" Were Considered to Be the "New World" for the Japanese

For the Japanese, the Russian Far East was the nearest foreign country in the old days. After the Meiji era, the people who sought a frontier built the Japanese society in Vladivostok at first and from there moved around to the various parts of Russia, and then eventually entered Manchurian Harbin. In this way, the Japanese have had a history of close relationship with "the north continent." This time period is much longer than the one for the Manchurian country, which appeared there later and lasted for 13 years from 1932 to 1945 .

Our purpose is to again discover a relationship between the Japanese and the northern places which were now completely forgotten, including the "Manchurian country" period, in line with a fact. ...

...The name of the journal, Sever, means "the north" in Russian, therefore, we wish to widely interact with the people who lived in the north continent, regardless of their nationality without limiting their Russian influence. ${ }^{* * * *}$

In summary, from the beginning, this journal has taken up relations with Japan and the northern places - mainly Vladivostok and Harbin. Even though Sever now offers wider themes, it continues being a unique journal concentrated mainly on the history of the "Russian Far East and former Manchurian" area.

One of the characteristics of the journal is its abundant presentation of memoirs. Subscribers can be described as many people who have a relationship to Manchuria - in particular Harbin — or Siberian internees and their descendants. Some of them want to write their own personal memories or those of their families, and some also want to receive information about old acquaintances.

*** For further information about the journal and workshop in Japanese, see: Ikuta M. (2008) "An angle to Harbin, in the case of Sever," News Letter, Association for the Modern and Contemporary History of Northeast Asia, No.20, pp. 13-27 (In Japanese).

**** Sever, No. 1, 1995, back cover (In Japanese). 
Their oral histories are also collected. Many valuable experiences and information could be forgotten if they were not documented now; publishing those records is one significant role of this journal.

However, Sever has gradually gained more readers and writers, and changes in its format have appeared. The number of pages has expanded from the original dozens of pages to a regular count of around 200; the space has been allocated to articles, book reviews, travelers' diaries, and so on. The founding members for Uchiyama, it was her father - are from Harbin, and they have personal experiences and networks in their study backgrounds, whereas most of the current members/researchers are from a generation without any direct connection with the Manchurian country. Articles and book reviews that researchers write must be reviewed by at least two anonymous reviewers as a condition for acceptance.

Just as the journal Sever allows everyone to contribute, the Sever workshop is basically open as well. The New Year's meeting, a gathering of around 30 people of various ages, has been regularly held for more than 20 years. Additionally, at any time, there are workshops or international symposiums with invited researchers. The latest international symposium, held in February 2019, had more than 70 participants, including expatriates and professors.

The workshop is gradually becoming well organized, and its expanding network is being noticed. One sign of progress for its institutional and network expansion was the establishment of the website (Google), https://sites.google. $\mathrm{com} / \mathrm{site} / \mathrm{severkharbinvladivostok/home,} \mathrm{in} \mathrm{the} \mathrm{spring} \mathrm{of} \mathrm{2016.} \mathrm{A} \mathrm{list} \mathrm{of} \mathrm{back}$ issue titles as well as guidance and information from the workshops is published there.

Harbin had been an international city where not only Chinese and the founding Russians coexisted, but people of various nationalities such as Jews, Germans, Polish, and Koreans were also part of the community. Therefore, Sever's network also includes Japanese, Chinese, and Jewish experts along with many others with different backgrounds. Still, the main group consists of Russia specialists, including more than 10 members of the Japan Association for Russian and East European Studies. The research field has also become more complex, as it now involves covering such disciplines as history, culture, literature, and economics. Regarding the Russian Far East and the former Manchurian area, documents of various languages such as Russian, Chinese, and Japanese are scattered about within present-day Russia, China, Japan, the United States (US), 
and so on. Therefore, this area of study is one where a global network is particularly required. Many experts from abroad also contribute papers to Sever, making it one of the global research centers for "Russian Far East and former Manchurian" area history (Sever's table of contents is also in Russian).

Because it is an open study organization with a wide variety of exchanges, it is not limited to only workshops. For example, the core members of the workshop have organized joint investigative trips to the former Manchuria several times $(2013,2016)$ in order to learn and share information together.

In this way, Sever, as both a journal and a workshop, is becoming more influential in the academic field, while at the same time continuing with its positive atmosphere of openness. In the author's opinion, this is an element necessary for maintaining its two roles of scientific study and the preservation of the historical memory. 